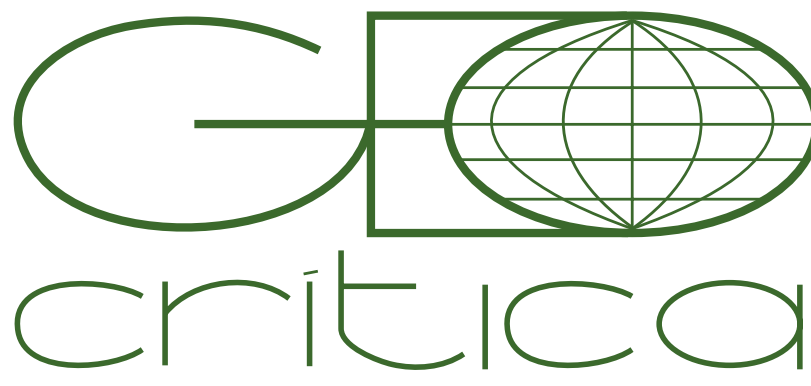

\section{Scripta Nova}

Revista Electrónica de Geografía y Ciencias Sociales Universitat de Barcelona

ISSN: $1138-97$

Vol. XXI. Núm. 579

1 de diciembre de 2017

\title{
LO COLONIAL COMO FUENTE DE AUTENTICIDAD DE LOS CENTROS HISTÓRICOS DE LAS CIUDADES MEXICANAS. EL DOBLE COLONIALISMO
}

\author{
Carlos Flores Rodríguez \\ Universidad Autónoma de Nayarit, México \\ Raymundo Ramos Delgado \\ Secretaría de Obras Públicas del estado de Nayarit, México
}

Recibido: 23 de febrero de 2017. Devuelto para correcciones: 26 de junio de 2017. Aceptado: 8 de agosto de 2017.

\section{Lo colonial como fuente de autenticidad de los centros históricos de las ciudades mexicanas. El doble colonialismo (Resumen)}

Bajo distintas concepciones y categorías, las originarias trazas y arquitectura de las ciudades empiezan a ser preocupación principalmente después de la segunda guerra mundial. Desde entonces, y ante una creciente industria de turismo global, la ciudad se ha convertido en un objeto de consumo de masas y de inversión inmobiliaria a la que se le ha exigido, para ser asimilable, una definición y una caracterización. Aunque en México desde la década de los años treinta del siglo pasado ya hay breves intentos, la instauración de políticas e instrumentos para su conservación se inicia cuatro decenios después.

Tomando como objeto la histórica ciudad virreinal de Tepic Nayarit, desde un enfoque historicista hermenéutico, en el presente trabajo se describe y se reflexiona sobre las consecuencias de su sujeción a un modelo idealizado de provincia mexicana, así como las posibles implicaciones que esta imposición genera en el natural desenvolvimiento de la imagen urbano-arquitectónica de esta ciudad media del occidente mexicano.

Palabras clave: Patrimonio urbano, colonialismo, memoria colectiva.

Algunos adelantos de esta investigación se presentaron en la $2^{\mathrm{a}}$ Bienal Internacional Territorios en Movimiento.

\section{The colonial as source of authenthicity of the historical centers of Mexican cities. The double colonialism (Abstract)}

Under distinct categories and conceptions, the original trace and architecture of cities has become important, especially after World War II. Since then, and under the growing global tourism industry, the city has become an object of mass consumerism and of real estate investment which has been required, in order to be assimilated, to have a definition and characterization. Although Mexico has had short attempts since the 30's, the establishment of policies and instruments for its preservation only started four decades later. Assuming that the city, by definition, is a social construct that exceeds all institutional pretense, taking as an object the historic viceregal city of Tepic Nayarit, from a hermeneutic historicist focus, this current work, describes and mulls over this phenomenon and its consequences of sticking through this idealized model of Mexican province, as well as the possible implications that this imposition generate and the natural unraveling of the urban-architectonic image of this intermediate city in western Mexico.

Key words: urban heritage, colonialism, collective memory 
Una ciudad no es una obra de arte, solo prospera si permite el cambio. El peligro surge cuando deja de ser capaz de reinventarse [...]. Deyan Sudjic

\section{Antecedentes}

Después de la segunda gran guerra, y por diversos motivos, a las ciudades se les han exigido constantemente que se definan en un ente asimilable ante una creciente industria del consumo global. En esta dinámica, y auspiciada por el neoliberalismo, la ciudad se ha convertido en un objeto del turismo de masas y de inversión inmobiliaria basada en su capacidad de diferenciación y caracterización cultural. La paradoja, sin embargo, es que a mayor presencia global, mayor presión existe hacia su homogenización para atender las necesidades culturales de todo tipo de inquilinos y consumidores temporales ${ }^{1}$. El nuevo ciudadano del mundo es un sujeto sin pertenencia de origen que trata de construir y consumir la cultura de otros lugares a partir del imaginario vivido o aprehendido.

En ese sentido, el patrimonio cultural edificado, no deja de ser parte de un proyecto económico redituable a partir de lo que la industria turística ofrece a los visitantes-consumidores: un conjunto de objetos tangibles e intangibles que legitiman las diversas etapas históricas y múltiples culturas regionales. No obstante, este fenómeno no ha dejado de estar inmerso en un proceso de transformación modernizadora que apela cada vez más a la invisibilidad y al desplazamiento de grupos sociales dentro de las ciudades, especialmente en lo que se ha denominado como centros históricos. Lo anterior vaticina, cada vez más, la tematización o museificación de las ciudades como parte de esta tendencia global en la que se incluye México.

En este tenor, la mayoría de estosnúcleosfundacionales delas ciudades mexicanas se ha convertido en los contenedores de un patrimonio cultural edificado que intenta reflejar la historia nacional. Por lo mismo, estos espacios se han transformado en un recinto de acumulación continua de diversos objetos arquitectónicos agrupados por un pasado común que, de alguna manera, conmemoran una pretendida inviolabilidad de la memoria colectiva a causa de las transformaciones presentes ${ }^{2}$. Por lo que estos centros históricos, volcados hacia esta conservación iconográfica de la arquitectura, si tienen que restaurar algunas capas de la vida cotidiana, lo harán siempre y cuando le sea redituable a esta cultura del consumo.

Ante las condiciones que tienden hacia la globalización, discursivamente el Estado mexicano ha tratado de reforzar un proyecto nacionalista en el cual se reconoce la diversidad cultural y el derecho que tienen los grupos sociales para definir sus tradiciones desde lo local y lo regional. La arquitectura y el urbanismo, entonces, representarían una compleja construcción social que dan testimonio de sus formas de vida pasada, por lo que la conservación de inmuebles históricos representaría un eje central en las políticas culturales. El resguardo sistemático de este patrimonio

1 Montaner y Muxí, 2013, p. 147.

2 Choay, 2007, p. 189-190. 
edificado, en su época moderna, si bien nace a partir de la creación del Instituto de Antropología e Historia (INAH), su interés, y los preceptos ideológicos que sustentan la conservación de la herencia cultural, se remonta a la etapa independentista del país en donde, desde una idealización de "lo indígena", el Estado mexicano, a partir de un discurso identitario, se autodesigna como defensor y, sobre todo, responsable de la identificación y definición de "lo nacional"3.

Después de la Revolución, estos organismos son renovados y, en algunos casos, reinstitucionalizados, lo que incluiría el discurso ideológico y la exclusividad. En ese sentido, y bajo un exacerbado nacionalismo, se crea el referido INAH como la entidad especializada y única para conducir la política cultural del país ${ }^{4}$, así como una estructura jurídica, especialmente con la promulgación de Ley Federal sobre Monumentos y Zonas Arqueológicos, Artísticos e Históricos (en adelante Ley Federal), a la cual, por el principio de supremacía jurídica, se sujetarían las leyes y ordenamientos estatales y municipales. Desde su origen, y a pesar de sucesivas modificaciones legislativas y de atribuciones ${ }^{5}$, el INAH ha conservado su carácter ambivalente de, por un lado, exclusivo protector del patrimonio de los mexicanos, y por otro, el de ser un ente ideológico del Estado, garante de la "conciencia nacional"6.

La centralización de estas atribuciones, entre otras cosas -tras someter a la cultura material bajo la presión del mercado turístico- ha colocado su desempeño en un plano vulnerable y cuestionable. Se coincide que uno de los problemas del INAH refiere a su cada vez más vacilante, débil, confusa y acomodaticia posición ante la defensa del patrimonio cultural ${ }^{7}$, particularmente el urbano y arquitectónico, a lo que debe añadirse la ya referida arrogación de imponer los criterios, métodos y técnicas para definir lo que es y lo que no es patrimonio y, por consecuencia, lo que es y lo que no es memoria, es decir, la identidad nacional y, por ese mismo principio -mal aplicado- de supremacía, la identidad regional y local.

\section{Tepic y su peculiar historicismo arquitectónico}

En Nayarit ${ }^{8}$, a partir del período gubernamental de 1987-1993, y en respuesta a la política nacional, se realiza una serie de acuerdos, declaratorias, catálogos y leyes concernientes a la conservación y protección de su patrimonio cultural edificado. Lo anterior se hizo en gran medida con el propósito de salvaguardar las pocas edificaciones de valor arquitectónico que aún existían tras un claro episodio de menoscabo y detrimento urbano arquitectónico perpetrado, especialmente, en la década

3 Yáñez, 2006, p. 52-53.

4 García, 2010, p. 103-107; Lombardo, 1997, p. 204-208.

5 Las modificaciones incluyen sucursales, llamadas Delegaciones, en cada estado del país.

Estas se localizarían en sus capitales y sus atribuciones se circunscribirían al territorio político administrativo de cada entidad federativa.

6 Ovalle, 2015.

7 Autores como Yáñez (2006) y Ovalle (2015) mantienen esta discusión.

8 Localizado al centro occidente del país, en la costa del océano Pacífico, se ubica el estado de Nayarit. La ciudad de Tepic, de origen virreinal y refundada en 1532 como capital de la Nueva Galicia, además de actual capital de este estado, constituye el asiento político del municipio del mismo nombre (figura 1). 
de los años cuarenta bajo el discurso del movimiento moderno9. Estas acciones, sin embargo, coincidieron con la postura ideológica del estado que buscaba la consolidación de una identidad regional afianzada en un imaginario colectivo construido, contradictoriamente, desde las instituciones federales y sus contrapartes estatales.

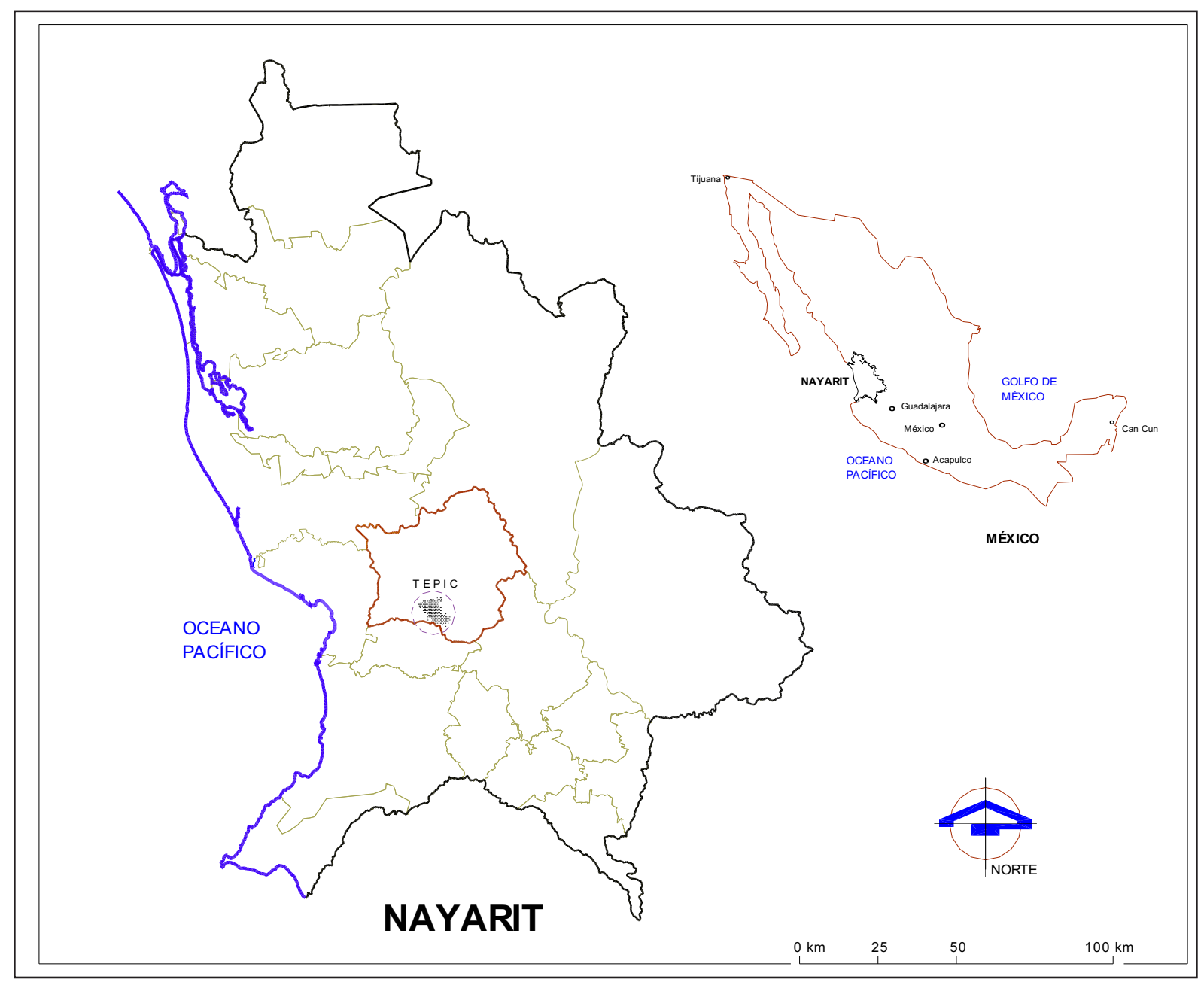

Figura 1. Localización de la ciudad de Tepic en el estado de Nayarit, México.

Fuente: Elaboración propia

Localmente, y en un intento de legislar regionalmente los esfuerzos compartidos por este ideario hacia la preservación de las diferentes formas culturales de la nación, se decreta el 20 de octubre de 1989 la Ley de Conservación, Protección y Puesta en Valor del Patrimonio Histórico y Cultural del Estado de Nayarit. Aunque en el nombre de la ley se advierta un universo más amplio de conservación patrimonial, en realidad se trataba de establecer una sujeción de los ayuntamientos en la identificación de sitios y monumentos que fueran aptos para su preservación para, precisamente, a través de un Consejo constituido exprofeso, incidir en el dictamen de las licencias de construcción en tales edificios; actividad que, hasta ese momento,

9 Flores, 2015, p. 144-155. 
continuaba como facultad exclusiva de los municipios de acuerdo al artículo 115 de la Constitución mexicana.

Desde esta legislación estatal, presurosamente se determinó qué era patrimonio histórico, turístico y cultural de interés local, lo que dio origen a su institucionalización desde el discurso de que su conservación era de utilidad pública. Un mes después, el 13 de noviembre de 1989, en un cuaderno de divulgación legislativa de la Cámara de Diputados del Congreso del Estado, se publicó el Acuerdo Ejecutivo de la Declaratoria de Inmuebles del Patrimonio Histórico y Cultural del Centro y Municipio de Tepic, donde se establecieron por primera vez los límites físicos del centro histórico de Tepic. Este se compondría de 146 manzanas que se incluirían en un polígono delimitado entre las avenidas Guadalupe Victoria al norte, Prisciliano Sánchez al oriente, de Los Insurgentes al sur, y Juan Escutia en conjunto con la calle Oaxaca al poniente. La zona, además, se habría subdividido en cuatro regiones a través de límites cartesianos formados por las avenidas México de norte a sur, e Ignacio Allende de oriente a poniente (figura 2).

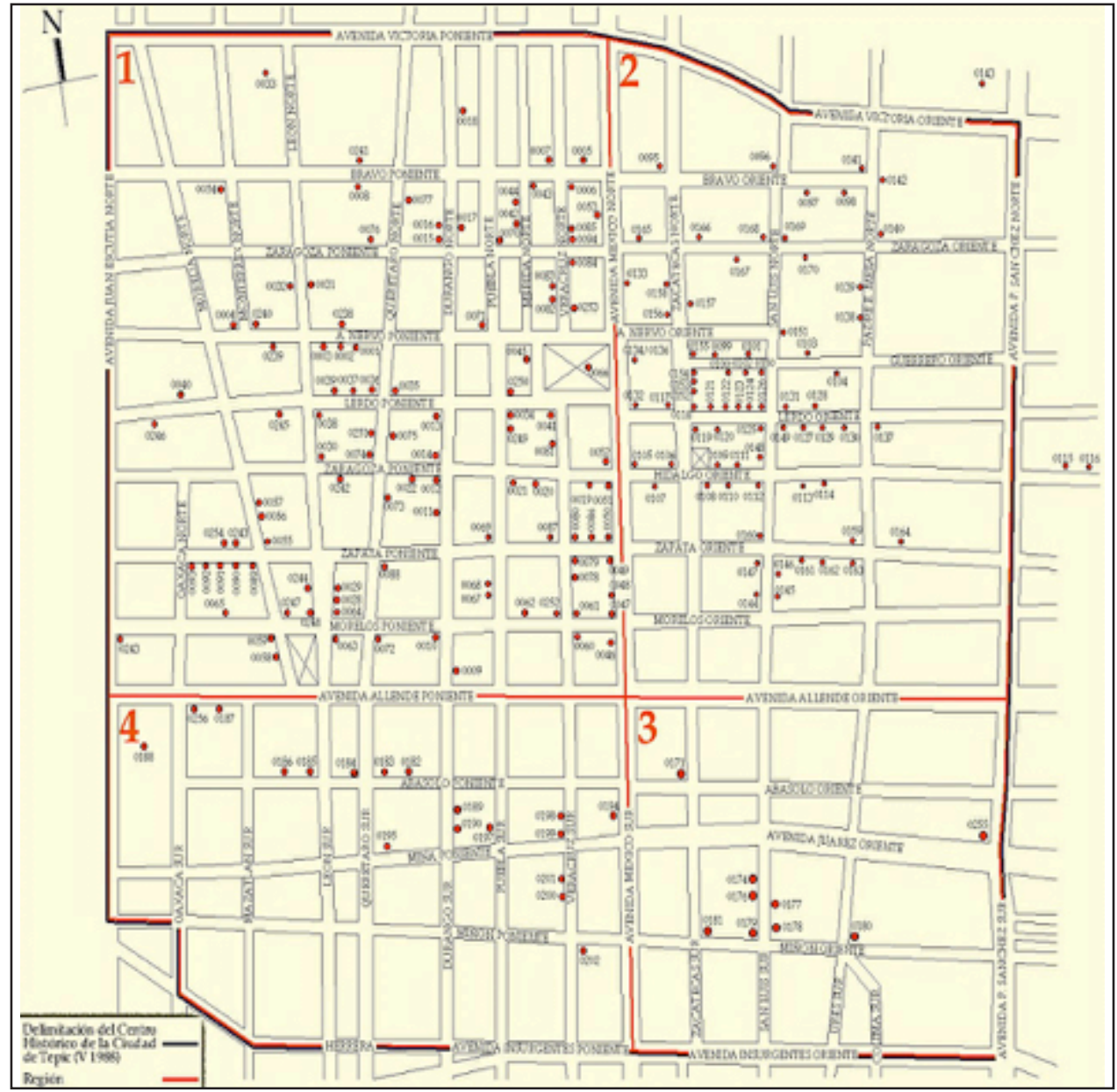

Figura 2. La delimitación del centro histórico de Tepic y la división de sus cuatro regiones. Los inmuebles catalogados por el INAH están señalados por un punto rojo con su respectiva clave del Catálogo Nacional de Monumentos Históricos Inmuebles. Fuente: INAH, 2000, p. 19-20. 
Primera reflexión. De acuerdo al origen histórico de la ciudad, y a la cartografía disponible, no queda claro si esta delimitación fue la más adecuada para designar al centro histórico de Tepic. Al revisar la cartografía aludida, y quizá en un afán de generar un paralelepípedo geométricamente regular, se observa una injustificada exclusión de gran parte de la periferia urbana del Tepic decimonónico ya que, según el artículo 10 de la citada Ley de Conservación de 1989, un centro histórico de una población es el:

[...] área de forma regular o irregular, comprendida en la trama urbana de trazo centenario 10 y tradicional, cuya relevancia histórica y tipo arquitectónico regional lo amerite y así se exprese en la declaratoria correspondiente.

Si el requisito para establecer los límites de un centro histórico es su traza centenaria, entendida como aquel tejido urbano que por lo menos tiene cien años, en realidad no fue así. Según la cartografía realizada en 1880, el área urbana de la ciudad de Tepic rebasaba por mucho las demarcaciones planteadas en la declaratoria de 1989 (figura 3). Como sea, este pragmático perímetro geométrico ${ }^{11}$, surgió desde el imaginario de las instituciones estatales con el patrocinio de las federales, en este caso representadas por el INAH, por lo que la displicencia y negligencia fueron compartidas.

Más allá de ello, no debe perderse de vista que la declaratoria de un centro histórico tiene por objetivo fundamental preservar todos aquellos inmuebles con valor patrimonial contenidos en esta estructura urbana histórica, tangible e identificable. De acuerdo a la referida Ley Federal de 1972, si bien no determina lo que es un centro histórico, sí apunta lo que es una zona de monumentos históricos. Según esta ley, y para nuestro caso, dicha zona define al área que congrega edificaciones relacionados con algún suceso nacional que se encuentre vinculado con hechos pretéritos relevantes, la cual se establece a partir de los análisis históricos que justifiquen este espacio, (artículo 41). De la misma manera, aquí se define como monumento histórico a aquellos "inmuebles construidos en los siglos XVI al XIX", es decir, los que se establecieron desde la cultura hispánica hasta el período porfiriano decimonónico (artículo 36).

\section{La idealización de lo colonial}

Desde la federación se había decidido elaborar un documento de compilación y clasificación del patrimonio edificado de la nación. Esta especie de catálogo de bienes culturales, que definirían la identidad arquitectónica nacional, estaría sustentado a partir de los conceptos establecidos en la citada Ley Federal de 1972. Realizado por cada delegación local del INAH, el catálogo buscaba identificar los inmuebles de valor patrimonial e histórico de las poblaciones, así como los elementos arquitectónicos

10 El subrayado es propio.

11 El trazo, excluiría una parte de la estructura urbana porfiriana y una gran periferia decimonónica que contenía barrios dedicados a distintas artes y oficios. Algunos inmuebles que formaban parte de estos, aún son visibles. 
que, se supone, sin contar las persistencias, habían permanecido y persistido ${ }^{12}$ en el espacio-tiempo de la ciudad.

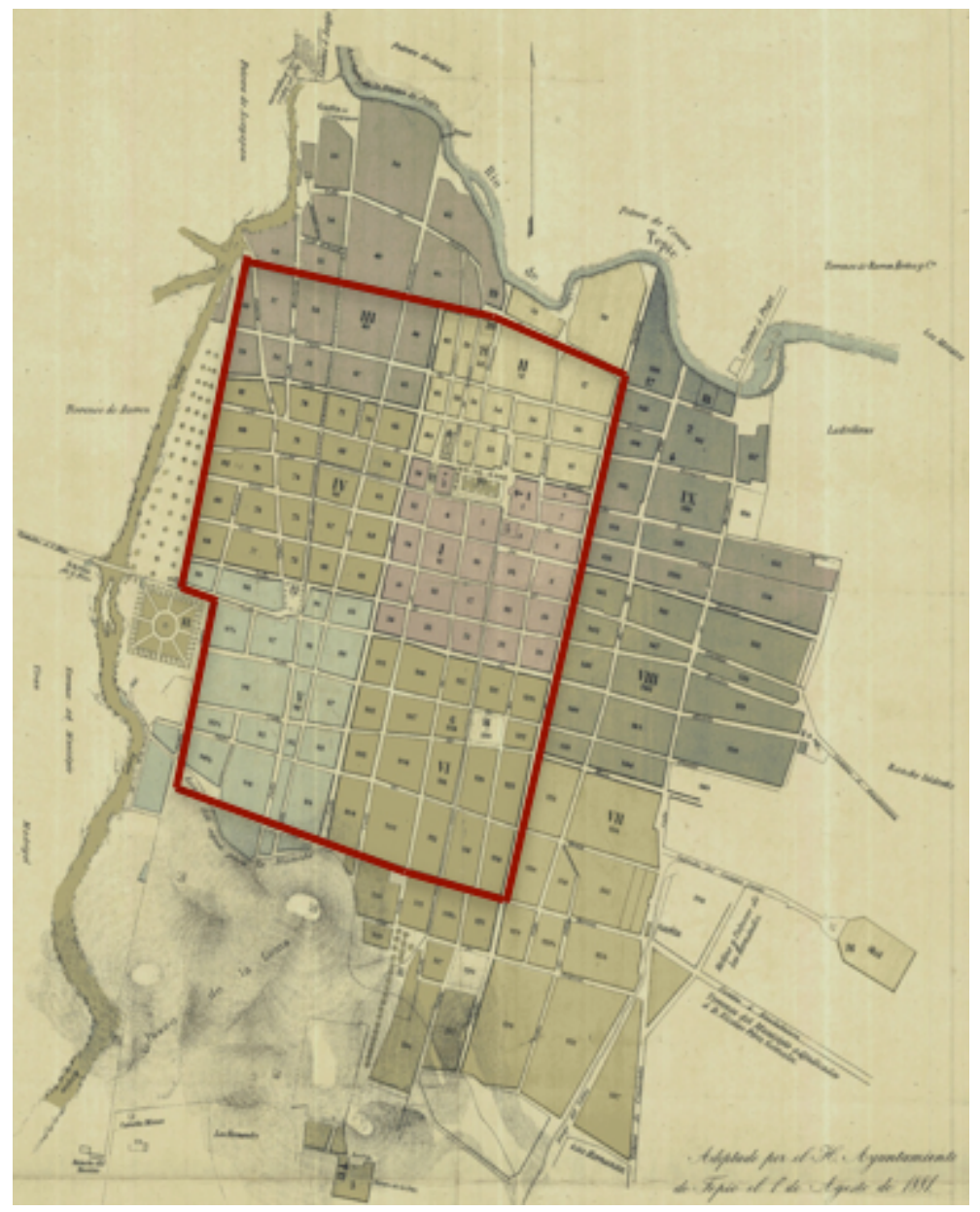

Figura 3. Plano de la ciudad de Tepic de 1880. Con línea roja se muestra el perímetro del actual centro histórico de Tepic.

Fuente: Huerta, 1883.

A principios de 1994, y para el caso de Nayarit, se inició la elaboración de un documento que finalmente se incluyó en el Catálogo Nacional de Monumentos Históricos Inmuebles dirigido, en este caso, por la Dirección de Monumentos Históricos del INAH, de la delegación nayarita. El inventario, en realidad, era una actualización y adaptación del realizado a finales de 1988 bajo el auspicio del Gobierno del estado de Nayarit y en el marco de las actividades ya referidas que incluía la declaratoria del centro histórico de Tepic. Este catálogo estatal, que abarcó solamente la ciudad de Tepic y sus alrededores, identificó, en una relación ordenada por domicilio, aproximadamente 1.370 inmuebles susceptibles de conservación y que se incluyeron en

12 La teoría de las permanencias de Marcel Poète y Pierre Lavedan refieren a elementos urbanoarquitectónicos de un pasado que aún experimentamos dentro de la ciudad. Las permanencias de las formas son los signos físicos de las relaciones de los habitantes hacia su ciudad, por lo que estos elementos no pierden su disposición y utilidad. En cambio, una persistencia es un hecho urbano que, aunque tiene características definidas en el momento de su origen, con el paso del tiempo transforman esa disposición y utilidad dentro de la ciudad. Rossi, 1981, p. 98-101. 
el Decreto para la Creación del Consejo Estatal de Protección del Patrimonio Histórico y Cultural de Nayarit, publicado el 11 de mayo de 1988 a través del Periódico Oficial de Gobierno del estado de Nayarit. Empero, de los 1.370, el INAH solamente consideró 257 inmuebles como monumentos históricos susceptibles de incluirse en su Catálogo Nacional; de ellos, contradictoriamente, 19 se encontrarían fuera del perímetro del centro histórico. Este cruce de conceptos legales y de competencias, específicamente en la definición e identificación de dichos monumentos históricos, además de provocar un vacío de valoración de más del 80\% de las edificaciones, suscita una segunda reflexión, en ese caso, a los criterios discrepantes de apreciación entre un nivel y otro.

Esta condición de subalternidad local solo es entendible con su opuesto complementario de, en este caso, etnocentrismo por parte de las instituciones federales. El Catálogo Nacional de Monumentos Históricos Inmuebles del INAH, para el caso de la ciudad de Tepic, se realiza con un sesgo hacia la arquitectura academicista, definida como aquella que se caracteriza por contener diseños ornamentales propios de un historicismo europeo. Con este apego, se dejó en la invisibilidad a la arquitectura decimonónica de manufactura tradicional ${ }^{13}$, así como cualquier otra corriente estilística más allá de lo histórico, por ejemplo, los monumentos artísticos ${ }^{14}$. A juicio del INAH, y en descargo, menos del 20\% del total de los inmuebles catalogados por el estado para el referido centro histórico tendrían estas características, sin embargo, en una contabilización alterna, y de acuerdo a la Ley Federal, particularmente por su condición decimonónica, la cifra de inmuebles se eleva a un 43\%. Así que, y como tercera reflexión, se advierte que aquellas construcciones decimonónicas de manufactura tradicional, institucionalmente podrían no tener el rango de arquitectura, pero, y contrario a su peculiar canon, pueden ser patrimoniales.

Después de casi veinticinco años de este ejercicio, el imaginario de las instituciones federales ha prevalecido sobre las estatales y municipales. Todo lo que posee un diseño arquitectónico constituido sobre corrientes estilísticas propias del porfiriato, se ha elevado a un nivel superior de valoración sobre cualquier arquitectura, sea tradicional, sea contemporánea. El lenguaje, incluso, usado para diferenciar un inmueble catalogado por el INAH, se acompaña con adjetivos grandilocuentes como excepcionales o relevantes, mientras que para aquellas construcciones no cataloga13 Las acepciones con que se ha identificado a este tipo de arquitectura no son unívocas, han variado entre tradicional, popular o vernácula. La primera acepción, refiere básicamente a valores entendidos que se transmiten por medio de una costumbre constructiva de generación en generación a partir de la historia familiar. En cambio, lo popular es definido como aquello que es perteneciente a la mayoría del pueblo y que, de alguna forma, se va reproduciendo de acuerdo al gusto constructivo de los habitantes de la ciudad. Por último, lo vernáculo es un adjetivo que determina la tipología arquitectónica de un inmueble por medio del ideario local, regional o nacional.

14 Sólo en el siglo XX, en el centro histórico de Tepic, se han construido, y convivido -con sus respectivas transiciones, manierismos y regionalismos-, tres corrientes estilísticas arquitectónicas: historicismo, modernismo y posmodernismo (Flores, Ramos y Luna, 2014). Así también existen discrepancias en el Catálogo Nacional de Monumentos Históricos Inmuebles del INAH al incluirse arquitectura posterior a 1900, la cual es injerencia del Instituto Nacional de Bellas Artes (INBA) según la Ley Federal (artículos 33 y 45). 
das, se utilizan adjetivos lacónicos como típicos (figura 4). Esta colonización ha ido más allá. La parte académica, aquella que por definición permanece incólume, se ha sometido también a este canon idealizado. De esta manera, a la suma de estos elementos estilísticos, y auspiciados por dicho Instituto, tanto coloquial como académicamente, se le ha establecido el calificativo de colonial.

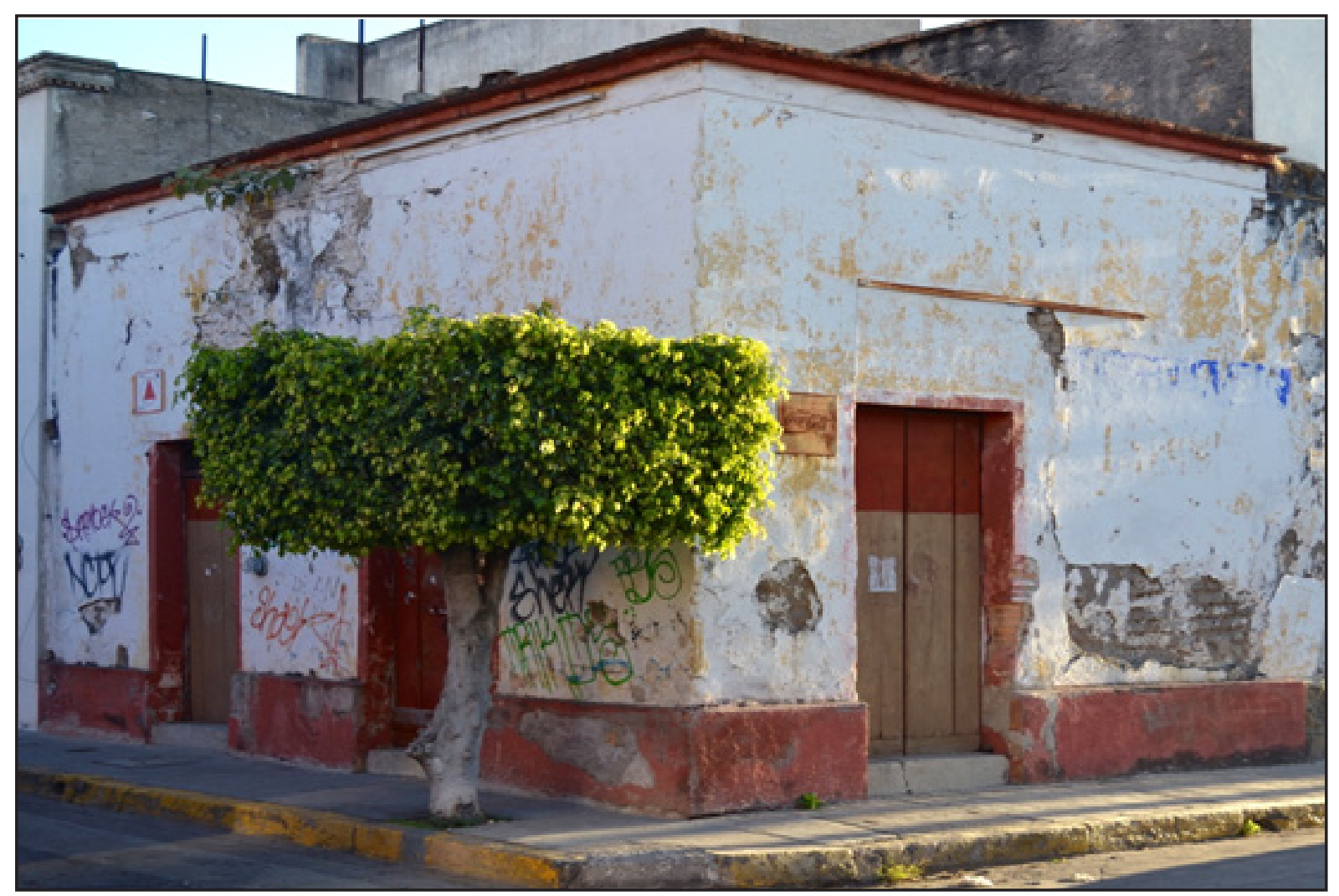

Figura 4. Edificación típica no catalogada.

Fuente: Carlos Flores.

Este desdén por lo "otro" avisa más consecuencias, particularmente en la reconfiguración del paisaje de la ciudad. En un análisis reciente del centro histórico de Tepic, del total de inmuebles identificados estatalmente, pero excluidos por la federación, el 28\% ya había sido demolido y el $61 \%$ habría sufrido, o un gran deterioro, o modificaciones a sus paramentos, a sus distribuciones arquitectónicas o a sus elementos decorativos, en su afán de imitar estos modelos academicistas del régimen. Un último fenómeno ha emergido con un rotundo impacto. Después de que la aprobación a cualquier modificación o construcción a realizarse en el centro histórico de Tepic ha sido trasladada a la delegación del INAH, las nuevas edificaciones, al igual que las sobrevivientes, imitan lenguajes combinados propios de este peculiar eclecticismo arquitectónico posmoderno y provinciano, emergiendo, consecuentemente, un paradójico falso histórico. 


\section{Discusión. Los colonialismos, algunos casos}

La ciudad, por definición, es plástica y demasiado compleja como para que pueda imponérsele límites ${ }^{15}$. Su dinamismo se manifiesta en sus edificaciones. En esta evolución, después de que la mayoría de los inmuebles catalogados son de propiedad privada, se ha generado una contradicción de intereses institucionales, tanto municipales como estatales, en contraposición con los particulares, debido a las restricciones que se les impone como obligación para su conservación. Sin embargo, y ante esta constante presión, estos lugares -reconocidos como parte de un patrimonio edificado y no como patrimonio social- en su conciliación, convenientemente han permitido ser colonizados por las instituciones evitando con ello una prolongada negativa en los posibles permisos de construcción. Así, la tematización turística, con fines de museificación, por medio de la implantación de un dudoso estilo colonial generado institucionalmente, se dilata. El cómo se ha llegado a ello, como cuarta reflexión, sólo puede entenderse por la cómoda pasividad municipal, reforzada con un avasallamiento federal y estatal.

Ante su impreciso conocimiento de la historia urbana y arquitectónica de la ciudad, las instituciones federales, y más recientemente las estatales, han idealizado al centro histórico de Tepic como un simple y estático contenedor de inmuebles de una etapa específica. Un signo de consolidación de este imaginario, es la emergencia de nuevas estrategias para la adaptación de las políticas turísticas estatales basadas en la pretendida autenticidad de escenarios urbanos, siempre que describan un solo período histórico de la vida nacional. Estos escenarios solo pueden consumarse arropados por una trivial pérdida de competencias bajo argumentos de dudoso fundamento legal. La variedad de interpretaciones que se le ha otorgado a este específico corpus jurídico desde las instituciones federales y estatales, inciden en el fomento de esta tergiversación arquitectónica de la ciudad. Así, el centro histórico de Tepic, en esta pretensión de reconocimiento a través de las instituciones, ha experimentado intentos de adaptación a un tipo ideal de ciudad turística en el que su arquitectura conforma en gran medida el escenario urbano. A esta arquitectura de manera espontánea e inmediata se le ha denominado colonial haciendo alusión, además de un pasado virreinal común, a que existe una homogeneidad edificatoria a partir de los estilos que se utilizaron en tal periodo. No obstante, y como dato contradictorio, más del 72 por ciento de los inmuebles catalogados por el estado se ubican temporalmente entre el siglo XIX y, especialmente, a principios del XX (figura 5); o sea, entre el independentismo y finales del porfiriato, periodo este último en que el eclecticismo tuvo su mayor auge ${ }^{16}$. Lo paradójico es que una corriente estilística que se caracteriza por su diversidad de lenguajes arquitectónicos, hablando propiamente del eclecticismo porfiriano, se vea amenazada por la inclusión progresiva de un simulado estilo colonial que, además de inexistente, busca la homogenización.

15 Lefebvre, 1972, p.130; Harvey, 1988, p.18

16 INAH, 2000, p. 21-385. 
La consolidación de este falso histórico dentro de la ciudad, a partir de esta nueva expresión estética de lo colonial, viene acompañada de una imposición de estandarización edilicia. El peligro de estas acciones es que, de manera paralela, se pretende hacer un museo urbano donde las transformaciones por el paso del tiempo son impensables y en el que, de manera arbitraria, se intenta una mayor valoración de esta fingida arquitectura colonial y un soslayo de la tradicional.

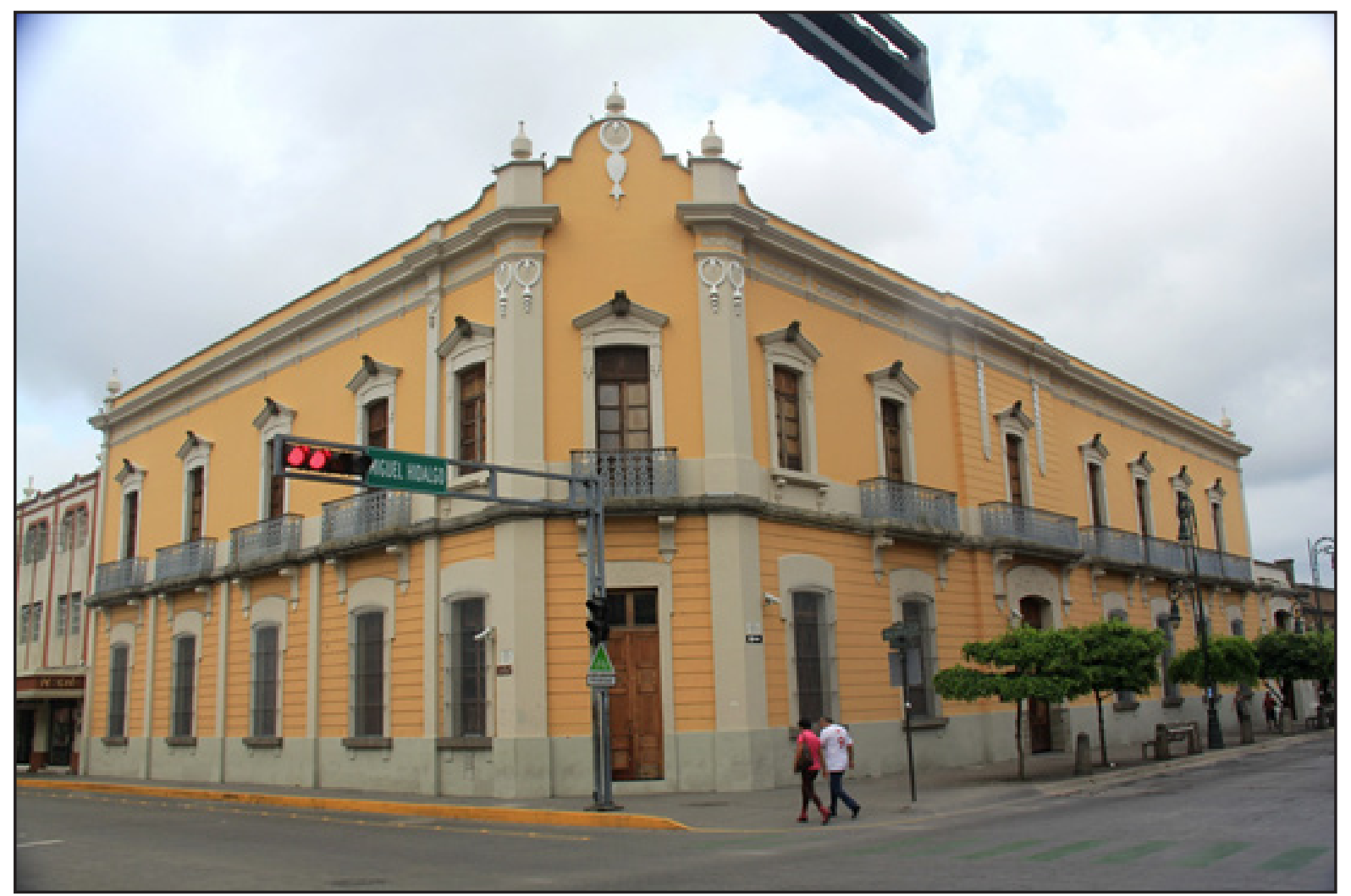

Figura 5. Antigua Casa Aguirre (Centro de Arte Contemporáneo Emilia Ortiz). Avenida México esquina con Miguel Hidalgo. Inmueble datado a finales del siglo XIX, la edificación responde a un eclecticismo, con elementos propios del neorrenacimiento.

Fuente: Jorge Gutiérrez.

Respecto al marco jurídico. Como se ha esbozado, desde el 2 de mayo de 1995 al Reglamento de Construcciones y Seguridad Estructural para el Municipio de Tepic, instrumento para conducir la política edificatoria municipal, se le anexaron ciertas normas técnicas al artículo 29 (aprobadas preliminarmente por el INAH) con la pretensión de mantener la fisonomía arquitectónica de los inmuebles catalogados por la federación. Este hecho, además de representar una invasión de competencias, invade la natural evolución temporal y espacial de la ciudad al comprometer no solo los edificios construidos, sino los aún no construidos. Así, el pasado, el presente y el futuro de un espacio de competencia municipal, dependen de un organismo de competencia federal.

Es importante advertir que, si la mejor manera de actualizar una ciudad, es respetando lo antiguo sin copiarlo ${ }^{17}$, en Tepic este aforismo es inválido. Aquí, no sólo 17 María y Campos, 2009, p. 147-148. 
existe una sanción sobre los inmuebles catalogados por el INAH, sino que, desde esta reproducción de ideologías institucionales, se trata de alienar, bajo el discurso de bienestar y desarrollo ciudadano, el derecho a la ciudad manifestado en su edificación. En la mayor parte del discurso se intenta mantener, a toda costa, una homogeneidad e inmutabilidad de los inmuebles catalogados por la federación, así como la adaptación de "los otros" que, por asumirse "diferentes", se busca su "integración" por medio de su altura, adhesión de volúmenes, alteración de vanos, sistemas constructivos e igualdad cromática.

No obstante que exista el recurso de integración arquitectónica y, sobre todo, la aprobación de tratados internacionales ${ }^{18}$, lo contemporáneo siempre quedará sujeto a este sui generis imaginario de la ciudad que posee la burocracia federal, relegando la posibilidad de creaciones arquitectónicas innovadoras y actuales dentro del centro histórico tepiqueño. Por ejemplo, y por mencionar los más representativos de este peculiar estilo colonial, en 1994, la remodelación y ampliación del Hotel Real de Don Juan, surge como modelo insigne de esta colonización e inicio de la implementación de este emergente y pobre lenguaje arquitectónico (figura 6). Ubicada en la esquina de la avenida México y la calle Javier Mina, si bien pareciera que esta creación fue producto de un imaginario de genealogía hollywoodense, sobrepuesta a la arquitectura nacional en la década del veinte, en realidad se trata de una justificación distorsionada de lo virreinal en Tepic. Bajo los mismos preceptos, siguieron la remodelación en 1995, y su ampliación de 2006, del Congreso del estado de Nayarit (fgura 7); la remodelación de la tienda departamental Fábricas de Francia en 1999 (figura 8), ambos sobre la avenida México; y, más recientemente, la construcción de un edificio en alquiler, también sobre la misma avenida (figura 9).

18 La Carta Internacional sobre la Conservación y la Restauración de Monumentos y Sitios de 1964, conocida como La Carta de Venecia, establece que cuando existan elementos arquitectónicos y urbanos a reemplazar y no se tengan pruebas indiscutibles de su composición o que su reconstitución este basada en conjeturas, será indispensable que su reposición lleve "la marca de nuestro tiempo" (art. 9), por lo que éstos "deben integrarse armoniosamente en el conjunto", distinguiendo de manera clara los componentes originales, evitando los falsos históricos y artísticos (art. 12). Semejante postura es suscrita en la III Asamblea del ICOMOS en Hungría, en donde se establece que, tratándose de edificios históricos, si bien son una basa, "debe prohibirse, totalmente, cualquier imitación". María y Campos, 2009, p. 145-146. 


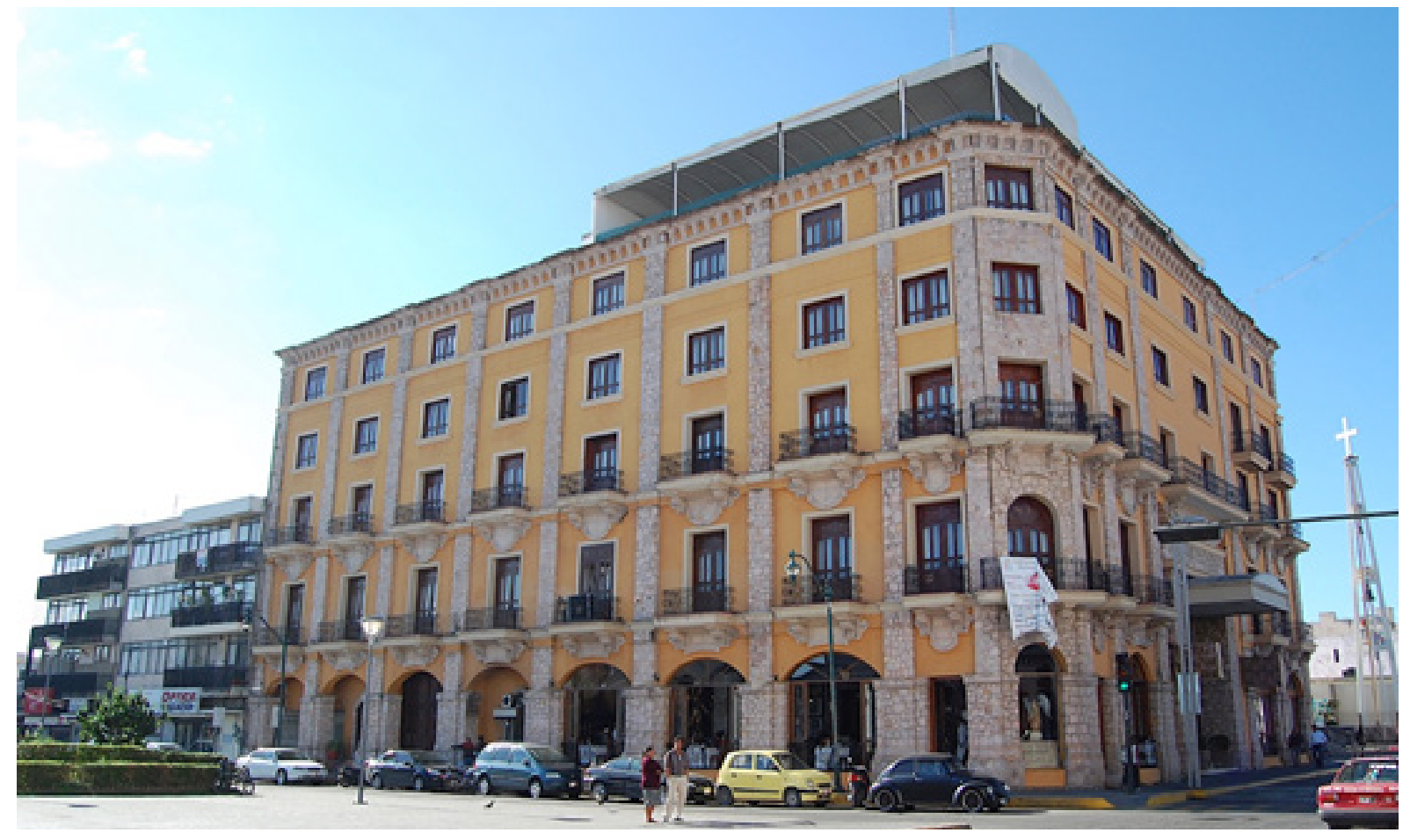

Figura 6. El Hotel Real de Don Juan. Avenida México esquina con Javier Mina. Desde que fue remodelado y ampliado en 1994, ha sido, institucionalmente, el modelo para homogenizar la imagen urbana del centro histórico de Tepic.

Fuente: Raymundo Ramos.

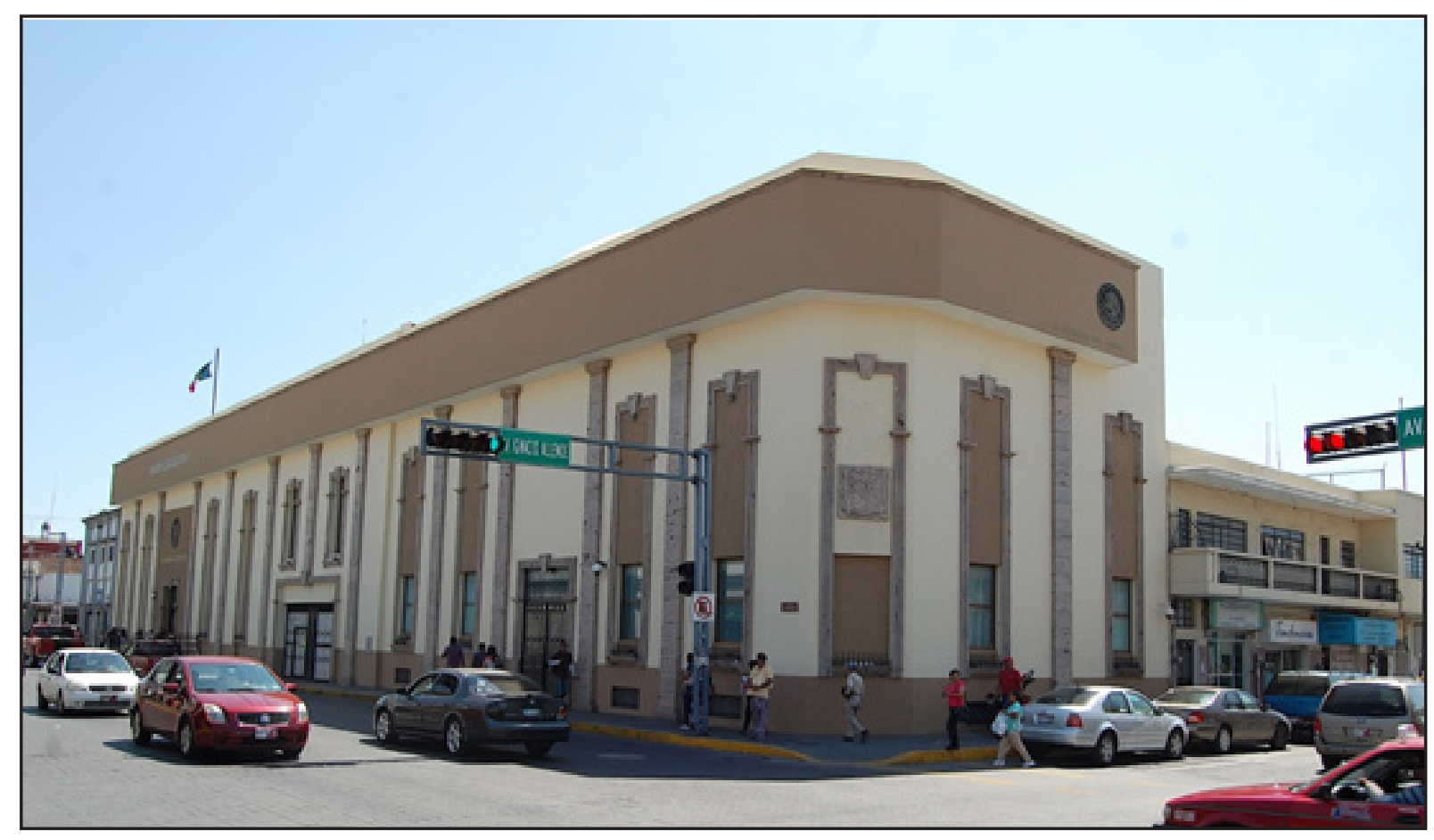

Figura 7. Sede del Congreso del Estado de Nayarit. En 1995 se intervino este inmueble sobre lo ya construido siguiendo el mismo patrón ornamental del Hotel Real de Don Juan.

Fuente: Raymundo Ramos. 


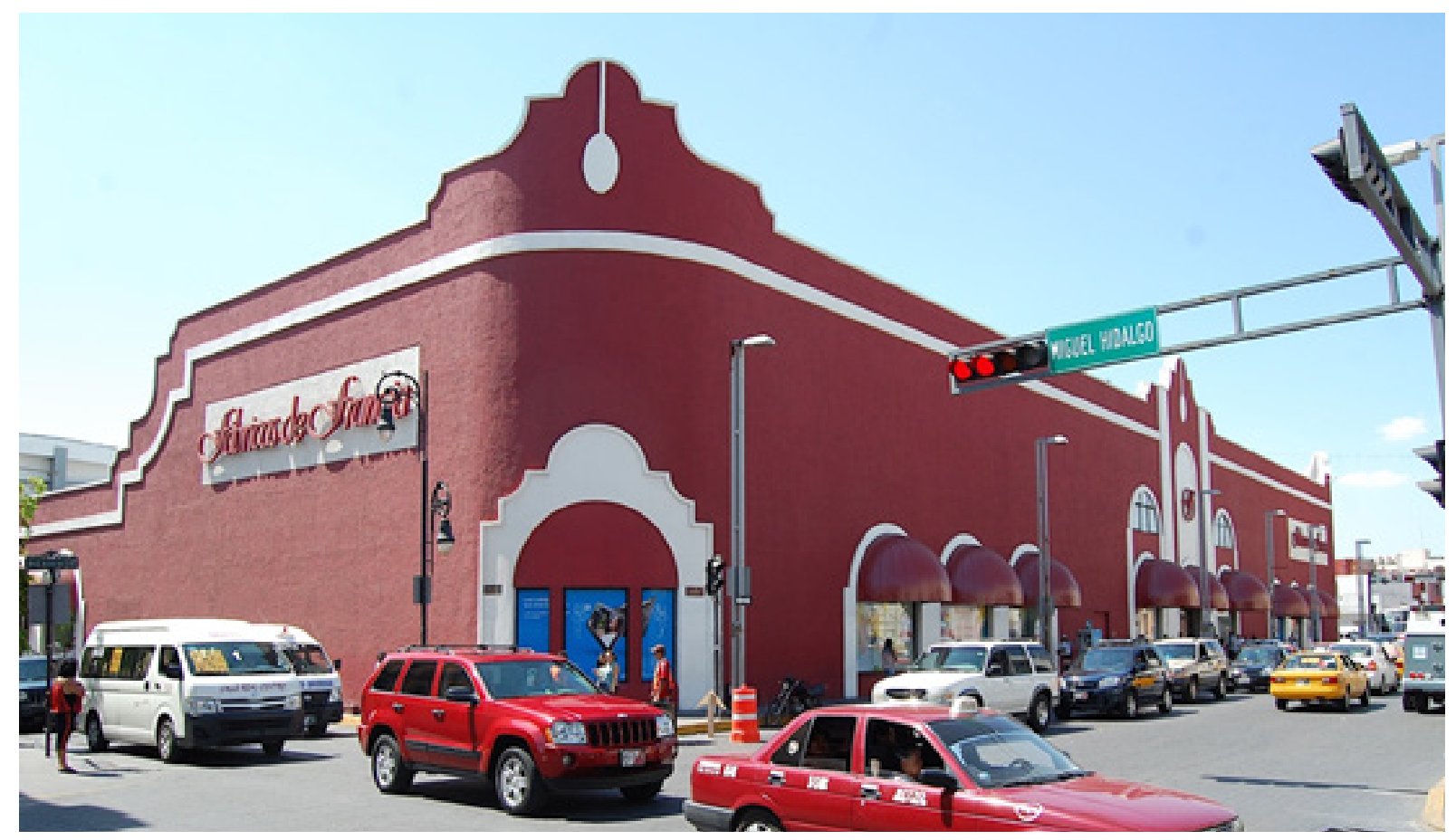

Figura 8. Tienda departamental Fábricas de Francia. Su ampliación en 1999, abarcó la totalidad de su manzana. Tratando de ocultar construcciones previas, levantó sus paramentos con grandes remates.

Fuente: Raymundo Ramos.

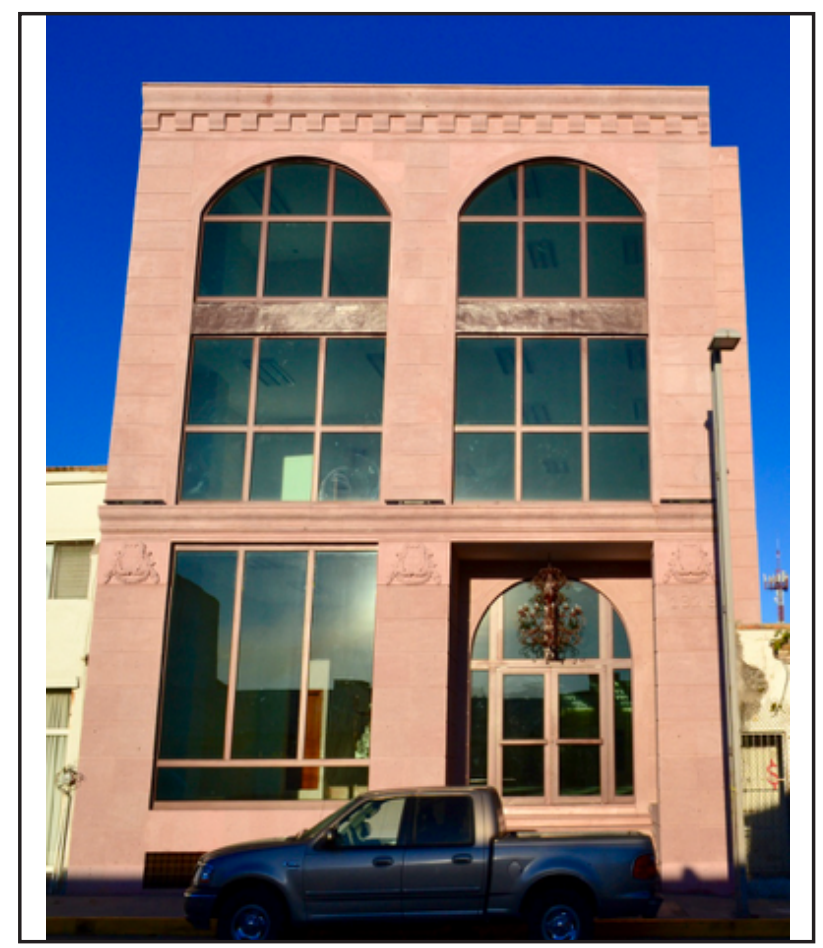

Figura 9. Edificio comercial en alquiler. La utilización de materiales y elementos decorativos, en especial la simbología en relieve simulando insignias con heráldicas, son parte del nuevo lenguaje.

Fuente: Carlos Flores. 
Este viario principal no es el único receptor del discurso. La mayoría de las avenidas perimetrales que seccionan el centro histórico, como la de Guadalupe Victoria, Juan Escutia, de Los Insurgentes, Prisciliano Sánchez, México e Ignacio Allende, y desde su centralidad, han sido los escenarios urbanos ideales para infiltrar poco a poco este supuesto novedoso lenguaje; aunque también existen otros ejemplos sobre calles secundarias que irrumpen de manera abrupta en el paisaje urbano establecido con este estilo, que más allá del citado linaje directo del neocolonial californiano -que mantenía este espíritu de los escenarios del incipiente cine de Hollywood ${ }^{19}$; es decir, el revival de un spanish colonial, en realidad se acerca más a un kitsch que, implacablemente, permea a la ciudad y a su sociedad.

\section{Reflexiones finales. Colonizando lo colectivo}

Si a la imposición institucional de la sui generis e irreflexiva narrativa colonial se suma la actitud pasiva de los dueños de los inmuebles, ciudadanos, asociaciones y organismos colegiados, la ecuación para la impronta de este novedoso estilo arquitectónico se completa. Las razones son variadas: los primeros, como se ha planteado, buscando obtener fluidamente una licencia de construcción; los segundos, desde la pasividad otorgada por años de imposición; y los últimos, usualmente con posturas clientelares unos, y corporativistas otros. Como sea, la arquitectura decimonónica originaria, no llenaría más las expectativas mínimas formales de la sociedad tepiqueña.

La reproducción de esta ideología de Estado, además del surgimiento e implantación de esta comprometedora nueva corriente estilística, ha posibilitado otro fenómeno: la suplantación de los saberes de la sociedad. En ambos casos, con el pretexto de proteger el pasado, paradójicamente se invade el derecho ciudadano a producir y conducir su estética. Anotemos. Si la memoria colectiva es la suma de memorias individuales ${ }^{20}$, ésta, como el pasado, es una (re)construcción no lineal, ni unívoca. No existe, se construye, se interpreta, se recrea. Es hermenéutica. De ahí que para conservarla precisa antes (re)elaborarla. El todo (lo colectivo) estaría incompleto si falta una de las partes (lo individual). El proceso, sin embargo, también es inverso. Lo colectivo, por evocación y repetición, puede convertirse (o influir) en lo individual, en la memoria del habitante. Así que, al incidir en lo aún no construido, se niega para la ciudadanía lo que se denomina el derecho de autoría de la ciudad ${ }^{21}$, es decir, este derecho a la ciudad de corte lefebvriano. Dicho de otra forma, se sustituye tanto la aspiración de belleza como los saberes de la colectividad.

Efectivamente, esta actitud ha suplido el imaginario y el derecho colectivo de lo que debe o no construirse en el centro histórico. Con ello, se han cancelado, a través del tiempo, competencias que han alienado sincrónicamente a los habitantes de la ciudad a través de una propaganda basada en la deducción inacabada de la ausente arquitectura del período virreinal. En otras palabras, el sometimiento sobre las

19 Anda, 2005, p. 43-45.

20 Halbwachs, 2004, p. 53-54.

21 Certeau, 1999, p.142-143. 
formas, ornamentos, materiales y colores de las edificaciones, buscando el mantenimiento y reproducción de una imagen urbana que nunca existió -aludiendo para ello la intención de protegerla de la propia sociedad que la creó- ha resultado, por paternalista e inoportuno, un factor de adulteración de la memoria colectiva. Así, contradictoriamente, este discurso colonizador ha dado como resultado, también: i) la exclusión de habitantes y constructores de bajo poder adquisitivo ${ }^{22}$, ii) la merma del municipalismo y del ideario colectivo, iii) la magnificación de iconos fundados en falsas imitaciones y, iv) la exclusión de nuevos diseños con la consecuente pérdida de la iniciativa y la diversidad urbana arquitectónica. Las instituciones, al reproducir este modelo eurocéntrico, además de monopolizar el conocimiento, paradójicamente institucionalizan la producción de la memoria colectiva.

Esta demanda de un paisaje urbano homogéneo y tematizado, aparte de romper con la cualidad de diversidad que toda ciudad debe poseer, ha derivado de forma directa en la transformación de las estéticas arquitectónicas actuales que, como linaje de interpretación, tienen un arraigo sobre un nacionalismo sesgado. El uso de una ornamentación, estructura y proporción específica en la conversión de los inmuebles que no se apeguen a este discurso formal ha conducido a la invisibilidad de otros períodos de la historia arquitectónica que aún permanecen, aunque débilmente, en la memoria colectiva de los habitantes y en la imagen urbana de la ciudad.

Por último, existe un temor desde las instituciones a asumir el riesgo de las creaciones urbanas. Parece que si no se controla la construcción de su imagen, ésta no será comercializable como producto de consumo. Aunque esta consigna lleva su cometido a una cultura del turismo, al mismo tiempo pierde una oportunidad para develar y generar nuevos y diversos hechos y discursos en la ciudad, particularmente aquellos que se encuentran fuera de los valores arquitectónicos hegemónicos. Quizá, contrariamente, la intolerancia e incomprensión hacia las autoridades de su cometido de defendernos de nosotros mismos nos impida elaborar, no sin una nota de cinismo, una última reflexión. ¿No estaremos, acaso, ignorando el nacimiento de un novedoso lenguaje arquitectónico posmoderno soportado en un también emergente nacionalismo provinciano? No lo sabemos. Como tampoco se tiene la certeza de que la tabula rasa sea la respuesta, aunque tanto la visión nietzscheana de la ciudad creativamente destructiva o destructivamente creativa, como la tensión baudeliereana de lo efímero de su existencia, se empeñen en coincidir con el conjuro de Katzman de que la arquitectura de la ciudad -de una ciudad viva-es, precisamente eso, una construcción constante sobre la cual existen períodos sucesivos de creación humana tan inoportunos como valiosos.

22 La construcción de un falso histórico es doblemente onerosa. Primero por el engaño -muchas veces incluso mal concebido--, en la utilización de un estilo, materiales y sistemas constructivos caducos o imposibles de igualar, representa un costo a la memoria histórica; y segundo, porque ese afán redunda en la importación de dichos materiales y mano de obra especializada, eventos que son reservados, en todo caso, a un segmento con alto poder adquisitivo lo que también redunda en una doble exclusión, la de cierto tipo de habitantes y la de cierto tipo de edificaciones. La otredad, -urbana, arquitectónica y societaria- se vuelve invisible. 


\section{Bibliografía}

ANDA ALANÍS, Enrique X. Una mirada a la arquitectura mexicana del siglo XX. Diez ensayos. 2da. ed. México: CONACULTA, 2005. 244 p.

CERTEAU, Michel; et. al. La invención de lo cotidiano 2. Habitar, cocinar. México: Universidad Iberoamericana, 1999.271 p.

CHOAY, Françoise. Alegoría del patrimonio. Barcelona: Gustavo Gili, 2007. 263 p.

FLORES RODRÍGUEZ, Carlos E. Ciudad, arquitectura y Sociedad. El Movimiento moderno en Tepic. Parte II: Urbanistica y Urbanización. México: UAN y UAS, 2015. 189 p.

FLORES RODRÍGUEZ, Carlos E; RAMOS DELGADO, Raymundo y LUNA JIMÉNEZ, Pedro. Arquitectura siglo XX Tepic. 2014, Manuscrito presentado para su publicación. 198 p.

GARCÍA MOCTEZUMA, Francisco. La planeación del desarrollo regional en México (1900-2006). Investigaciones Geográficas, Boletín del Instituto de Geografía, UNAM, 2010, no. 71.p. 102-121.

HALBWACHS, Maurice. La memoria colectiva. Zaragoza: Prensas Universitarias de Zaragoza, 2004. $190 \mathrm{p}$.

HARVEY, David. La condición de la posmodernidad. Investigación sobre los orígenes del cambio cultural. Buenos Aires: Amorrortu, 1998.401 p.

HUERTA, Victoriano (Encargado). Plano de la ciudad de Tepic. Levantado por los Oficiales del Cuerpo Especial del Estado Mayor: capitán $1^{\circ}$. Victoriano Huerta, capitán $1^{\circ}$. Joaquín Beltrán, capitán $1^{\circ}$. Alejandro Armendáriz, capitán $2^{\circ}$. Antonio Flores, capitán $2^{\circ}$. Francisco O. Morales. Marzo de 1880. Escala 1:5000. 87 x 64 cm. México: Servicio de Información Agroalimentaria y Pesquera, Mapoteca Manuel Orozco y Berra, 1883.

LOMBARDO DE RUIZ, Sonia. El patrimonio arquitectónico y urbano (de 1521 a 1900). En FLORESCANO, Enrique (coord.). El patrimonio Nacional de México. México: CONACULTA y FCE, t. II, 1997. p. 198-240.

LEFEBVRE, Henry. La revolución urbana. Madrid: Alianza, 1972. 198 p.

INSTITUTO NACIONAL DE ANTROPOLOGÍA E HISTORIA (INAH). Catálogo Nacional de Monumentos Históricos Inmuebles del Municipio de Tepic. Tepic: INAH, 2000. $467 \mathrm{p}$.

MARÍA Y CAMPOS CASTELLÓ, Alfonso. La arquitectura del presente en el espacio histórico. En CENTRO CULTURAL DE ESPAÑA EN MÉXICO (editor). VII encuentro Internacional de Revitalización de Centros Históricos. La arquitectura de hoy, entre la ciudad histórica y la actual. México: CONACULTA, 2009. p. 145-149.

MONTANER, Josep María y MUXÍ, Zaida. Arquitectura y politica. Ensayos para mundos alternativos. Barcelona: Gustavo Gili, 2013.253 p.

OVALLE HERNÁNDEZ, Víctor Manuel. El INAH: entre la preservación y la mercantilización del patrimonio histórico-cultural de México [en línea]. México: Arkeopatias, 10 de diciembre de 2015. Disponible en https://arkeopatias.wordpress. com/2015/12/10/el-inah-entre-la-preservacion-y-la-mercantilizacion-del-patrimonio-historico-cultural-de -mexico/ 
ROSSI, Aldo. (1981). La arquitectura de la ciudad. $2^{\text {a }}$ ed. Barcelona: Gustavo Gili, 1981. $311 \mathrm{p}$

YÁÑEZ REYES, Sergio. (2006). El Instituto Nacional de Antropología e Historia: antecedentes, trayectoria y cambios a partir de la creación del CONACULTA. Cuicuilco, vol. 13, nº. 38, septiembre-diciembre, 2006. p. 47-72.

(c) Copyright: Carlos E. Flores Rodríguez, 2017

(c) Copyright Scripta Nova, 2017.

Ficha bibliográfica:

FLORES RODRÍGUEZ, Carlos E., RAMOS DELGADO, Raymundo.Lo colonial como fuente de autenticidad de los centros históricos de las ciudades mexicanas. El doble colonialismo. Scripta Nova. Revista Electrónica de Geografía y Ciencias Sociales. [En línea]. Barcelona: Universidad de Barcelona, 1 de diciembre de 2017, vol. XXI, no 579. ISSN: 1138-9788. 